\title{
INFLUENCE OF THE TILT ANGLE OF LANCES ON THE FLUID FLOW INSIDE THE GASIFIER SHAFT
}

\author{
P.V. Openyshev ${ }^{1, *}$, and M.A. Sheremet ${ }^{1,2}$ \\ ${ }^{1}$ Tomsk Polytechnic University, 634050 Tomsk, Russia \\ ${ }^{2}$ Tomsk State University, 634050 Tomsk, Russia
}

\begin{abstract}
Fluid flow inside the vertical gasifier shaft having the granular porous phase has been numerically analyzed. The effect of the tilt angle of lances for air injection on the fluid flow has been studied. The distributions of the temperature, particles volume fraction and trajectory of particles motion inside the gasifier shaft have been obtained. The results clearly show an essential effect of the tilt angle of lances on fluid flow and heat transfer.
\end{abstract}

\section{Introduction}

There is strong interest to electric power installation for producing synthetic gas from solid fuels at the present time. Topicality of development of gas-generator installations consists in more effective utilization of waste of the industry and fuels with low fuel heat capacity. Moreover a transition to gas-generator technology promotes conservation of relatively small petroleum and natural gas reserves [1-3].

The production problem of gasifiers is the lack of reliable engineering methods for an analysis of such equipment. Development of mathematical models based on the analysis of physical-chemical characteristics of the gasification process is the actual scientific task due to its solution can significantly accelerate the design stages of gas-generator plants $[4,5]$.

The aim of this work is the numerical simulation of unsteady two-phase flow and heat and mass transfer in the gasifier shaft.

\section{Physical model}

We consider a two-dimensional channel model of the gas generator shown in fig. 1. Coal bed of the height of $525 \mathrm{~mm}$ is considered as the granular porous phase. Air is supplied to the bottom of the channel through the lances symmetrically inclined at an angle $\alpha$ and moves upward with velocity in the inlet section of $40 \mathrm{~m} / \mathrm{s}$ and a temperature of $1000^{\circ} \mathrm{C}$. It should be noted that the model does not take into account the phase transformations. In this case, we have analyzed two-phase flow and heat transfer without gasification process inside the considered channel.

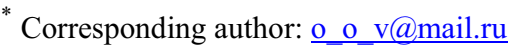


Numerical simulation of two-phase flow and heat transfer in the channel of the gasifier has been conducted using the computational fluid dynamics package "Fluent" [6]. Geometric model with finite element mesh consisting of rectangular and triangular elements with a minimum size of $5 \mathrm{~mm}$, has been created in the preprocessing program "Gambit" [7]. Further the mesh has been exported to the software package "Fluent". Further on using this software we have defined completely all phases properties, boundary conditions and parameters of the numerical method. It should be noted that the difference scheme "QUICK" has been used for an approximation of convective terms. Difference scheme "PRESTO" has been used for the pressure definition in the Poisson equation. Simultaneous determination of the velocity and pressure fields has been realized on the basis of the "SIMPLE" algorithm.

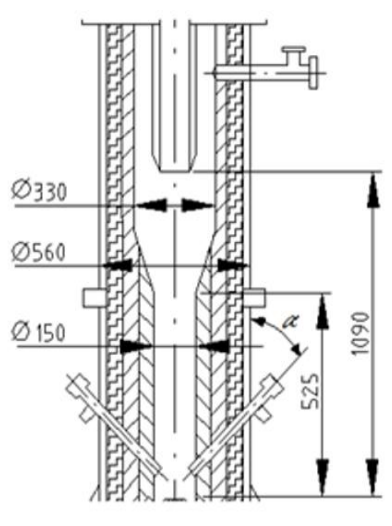

Fig. 1. The schematic of the gasifier shaft.

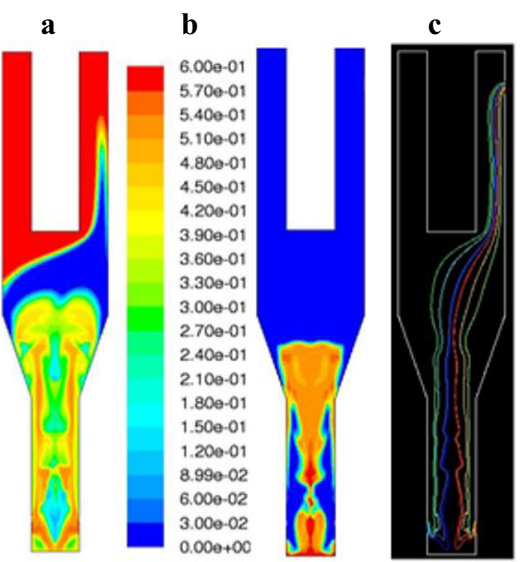

Fig. 2. Distributions of the temperature (a), particles volume fraction (b) and trajectory of particles motion (c) for $t=0.35 \mathrm{~s}$ and $\alpha=15^{\circ}$.

We have analyzed an influence of the lances mounted in the lower part of the gasifier shaft, on the flow structure and heat transfer for different time moments $0.35,1$ and 2 seconds and various inclination angles of the lances $\alpha=15^{\circ}, 45^{\circ}$ and $75^{\circ}$.

It should be noted that the simulation of fluid flow and heat transfer in the case of twophase flows has been conducted using the Euler approach (continuum model). Continuum model allows to analyze the two-phase flow as a motion of two interacting continuums associated with the carrying agent and particles [8]. It is assumed that the dispersed phase is represented as a continuum with the density that is continuously distributed in space. Parameters of this continuum are considered as local average values of particle parameters. The behavior of the two-speed and two-temperature continuum is described by the equations of continuum mechanics in Euler variables. Interaction of phases is achieved by interfacial exchange coefficients. Such interaction depends on the phase type. The properties of granular flow are determined based on the kinetic theory.

\section{Results and discussion}

At the initial time $(t=0.35 \mathrm{~s})$ distributions of thermal hydrodynamic characteristics (fig. 2) for the inclination angle of lances $\left(\alpha=15^{\circ}\right)$ represent non-significant mixing at the bottom of the gas-generator shaft, that illustrates symmetry fields of temperature and particles volume fraction in a straight-flow zone. The complicated structure of trajectories of the dispersed and continuous phases is observed for the lances inclination angles of $45^{\circ}$ and $75^{\circ}$ for $t=0.35 \mathrm{~s}$, in contrast to the results presented in fig. 2 . However, the high speed of inject- 
ing air $(v=40 \mathrm{~m} / \mathrm{s})$ for the inclination angle $\alpha=15^{\circ}$ causes the severe non-uniformity in the distribution of the dispersed phase volume fraction inside the channel with time (fig. 3). Such heterogeneity is not observed for injecting angles of $75^{\circ}$ and $45^{\circ}$, namely, the dispersed phase motion occurs along the channel surfaces.

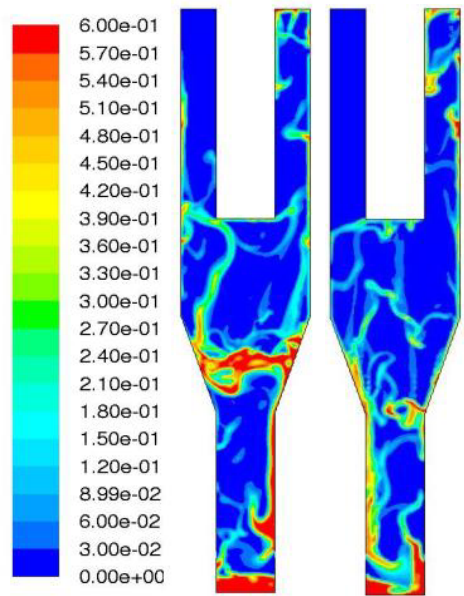

Fig. 3. Distributions of particles volume fraction for $\alpha=15^{\circ}, t=1 \mathrm{~s}$ (left contours) and $t=2 \mathrm{~s}$ (right contours).

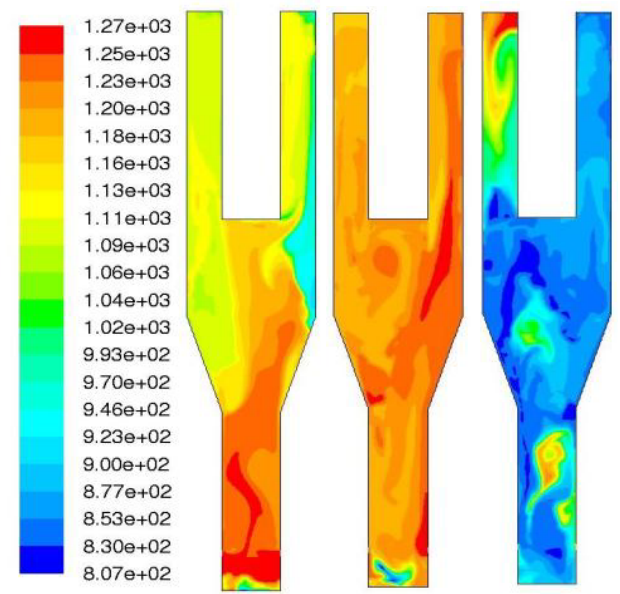

Fig. 4. Distributions of the temperature for $t=2 \mathrm{~s}$, $\alpha=75^{\circ}, 45^{\circ}, 15^{\circ}$ (from left to right).

The typical temperature distributions for the gasification process can be found for $t=2 \mathrm{~s}$ and $\alpha=75^{\circ}$, where the zones of dry distillation and drying the fuel are allocated in the upper part of the shaft (fig. 4). It should be noted that the resulting high values of temperature in these areas are due to the absence of endothermic reactions occurring in the gasifier. Distributions of thermal hydrodynamic characteristics for $\alpha=45^{\circ}$ differ non-significantly from the results obtained for the angle of $75^{\circ}$ at different times.

This research is not sufficient and further work is required to identify the optimal range of inclination angles for the lances.

The research was realized with financial support of Minobrnauki of Russia in framework of FTP "Research and development in prior direction of scientific-technological complex of Russia in 2014-2020 years", unique R\&D identifier RFMEFI58114X0001.

\section{References}

1. A.F. Ryzhkov, A.V. Popov, Energetic 10 (2012)

2. A.V. Remezov, V.V. Chumak, J. Vestnik KuzGTU 2 (2005)

3. S.A. Tsybulsky, Modern coal gasification technology in industrial power (Tomsk Publ., Tomsk, 2014)

4. I.G. Donskoy, Modelling and optimization of operating modes of the dense layer of the gas generator for the combined-cycle thermal power plant (Diss., Irkutsk, 2014)

5. P.V. Openyshev, M.A. Sheremet, Key Eng. Materials 685 (2016)

6. O.V. Baturin, N.V. Baturin, V.N. Matveev, Computation of the fluid flow using the software package "Fluent" (Samara Publ., Samara, 2009)

7. O.V. Baturin, N.V. Baturin, V.N. Matveev, Construction of computational models in the preprocessor "Gambit" of the software package "Fluent" (Samara Publ., Samara, 2009)

8. K.N. Volkov, V.N. Emelyanov. Flows of gas with particles (Moscow Publ., Moscow, 2008) 